\title{
The Potentiality of E-recruitment System for Schools and Hospitals in Moshi Catholic Diocese
}

\author{
Fr. Vumilia, ${ }^{1}$; Onyancha, $\mathbf{E}^{2}$; Mtenga, $\mathbf{T}^{3}$ \\ Mwenge Catholic University - Moshi, Tanzania
}

\begin{abstract}
The adaptation of e-recruitment is a very complex phenomena as its tends to address numerous organization obstacles and overcoming operative cost. In this digital era, many organizations' human resources prefer to use a set of digitalized appliances to identify new employees and examine their credentials, certifications, and characteristics. This study was conducted to examine the utilization of erecruitment system in Moshi Catholic Diocese. The study was guided by three specific research objectives stated as: Firstly, to find out the extent to which e-recruitment system has been successful in MCD. Secondly, to eximine the benefits of e-recruitment system in MCD. Lastly, to asses the challengers of utilizing e-recruitment system in MCD. Additionally, the study useda cross-sectional design where by70 participants were sampled through stratified, purposive, and simple random sampling employed to sample Catholic Diocesan institutions. Furthermore, a questionnaire and structured interview used to collect data from the respondents, and the validity and reliability of the instrument was considered. Data collected analyzed through descriptive (mean, standard deviation, and percentages) and inferential statistics (chi-square test). The findings revealed that the Catholic Diocese of Moshi is using e-recruitment system in the whole process of hiring employees in their respective Schools and Hospitals higher than traditional approaches. Moreover, the method brought huge advantages to their institutions as most of the employees hired were found to be extremely reliable for the work assigned and effectively in the task implementation.
\end{abstract}

\subsection{Introduction}

\subsection{Background of the Problem}

E-recruitment is the transformation of conventional paper-based recruitment practices into a highly streamlined and digitalized process(Belisari \& Appolloni, 2020). The adaptation of e-recruitment is a very complex phenomenon as it tends to address numerous organizational obstacles and overcoming operative costs. In this digitalized era, most organizations' human resources prefer to use a set of digitalized appliances to identify new employees and examine their credentials, certifications, and characteristics (Innocent \& Kalaskar, 2016; Mohammed, 2013).In today's competitive environment, companies must excel at their operations and increase their productivity improvements through technology adoption to survive and succeed over future rivals. Efficacy, quality, and creativity are both linked to the pace at which clients are served which is critical throughout industries as well as in hospitality and spiritual institutions.

Anyone who works in HR must be well aware of how tiring and time-consuming the recruiting process is as well as not to mention the actual costs incurred(Tambe \& Yakubovich, 2019). Artificial Intelligence (AI) has made this process less extensive (Thomas, 2019). Companies automated screeners that detect skills on a candidate's resume. This has made hiring decisions extremely easy in the early stages of recruiting (Reis \& Melão, 2020). The people in the HR department no longer need to go through tens of thousands of emails and sort through them. They can simply use screeners to sort them out within seconds (Dey \& Ramos, 2009).

As in the search for various products and services in this digital age, many organizations and companies focus on finding the best employees through online systems as it saves time, is paperless, and can manage many customers within a limited time (Bhaktimayanand, 2010). Although this section is not well developed but is often associated with a wide range of terms such as e-recruitment, online staffing, online sourcing, and 
the rest(Jiarakorn \& Pasipol, 2015). E Staffing is a component of human resources recruitment in which the contractors use the internet to find temporary or permanent employees(Akila \& Thirumagal, 2020). Many developed countries have been using this system of recruitment in finding and hiring highly skilled workers from different countries and thus directly benefiting from the use of the internet in finding better employees(Fachrizal \& Manik, 2019). This issue is particularly challenging for African countries and many developing countries where the e-recruitment issue seems to be emerging more and more for hiring and staffing companies, with organizations turning their backs on this sector and rely much on e-recruitment.

According to Melanthiou (2015), approximately 79\% of the Global 500 of the world's firms with high gross sales hire staff from their websites. The survey conducted by Kaur (2015)indicated that the percentage of corporations that use e-recruiting increased from $28 \%$ in 1997 to $95 \%$ in 2005. There are also online work boards, in addition to corporate websites such as hot jobs,hire.com, CareerBuilder, monster.com, and headhunter.net are some of the well-known work boards globally. Employment applicants submit their resumes through online job boards to adapt their qualifications to open positions. Organizations benefit from online recruitment because it is a current hiring tool that offers current intelligence, opens up regional boundaries for talent searches, and saves time and money (Chuong, 2017). A magazine can demand range from 50to 100 United States Dollars(USD) to publish a job advertisement, whereas ads on the web cost even less than USD 10 per item. Fred and Kinange, (2018)indicated that the e-recruitment system reduced the recruiting expense from USD 1383 endured traditional recruitment to USD 183 using an e-recruitment scheme (Reis \& Melão, 2020).

Tanzania's internet system has resulted in significant changes in the country's communication infrastructure. In 2012, the country was linked to the international fiber-optic cable (SEACOM) in Dar-es-Salaam in July 2009 (SubTel Forum, 2013). This substantially facilitated the growth of the internet. The changes lead to the rise of mobile phone use and a rise in the number of internet cafés owners predominantly in major towns mostly often Mwanza, Arusha, and Dar-es-Salaam (Behitsa \& Diyamett, 2015). The advent of mobile data and $3 \mathrm{G}$ wireless broadband has increased the use of internet services across the country (Swarts \& Wachira, 2010). By the middle of 2009, there were above 20 internet facility benefactors registered, and Internet usage had ascended by 1.3 percent, with 520,000 subscribers (BuddeComm, 2013).

Most organizations and institutions in Tanzania have websites that are also used for recruiting. Some businesses may hire their employees or outsource to specialized recruiting firms. Several macro and microfinance organizations, including banks, use the internet to recruit employees(Thomas, 2019). Furthermore, commercial firms such as Vodacom Tanzania, Zantel, Mohammed Enterprises Tanzania Limited (METL), Coca-Cola Tanzania, social institutions, and non-governmental organizations (NGOs) are among the organizations that use online recruiting tactics. These organizations and businesses used to advertise job openings on their homepages to attract job searchers(Lipumba, 2018). For instance, Tanzania's public sector is consolidated under the Tanzania Public Service Recruitment Secretariat, which is in charge of publicizing all job openings in all government sectors, such as ministries (http://www.ajira.go.tz).

\subsection{Statement of the problem}

As the amount of firms grows and the human resource climate becomes more competitive, the labor force becomes a crucial sector in Tanzania. Despite having a large wave of unemployed youth, finding a better worker is still a major challenge. According to the United Nations Conference on Trade and Development, foreign direct investment in Tanzania has increased rose from USD 938 million in 2017 to USD 1.1 billion in 2018(UNCTAD, 2019). As a result, human resource administrators are concentrating on the right ways to hire new employees and keep existing ones in their organizations. Religious institutions have been facing severer hiring challenges specifically in getting the employees who corresponding to preliminary demographics requirements. Poor communication skills, a high rate of employee turnover, false representation, and a huge pond of unqualified candidates, as well as outdated recruiting techniques have been several reported by recruitment agencies in Tanzania (Lipumba, 2018). The Moshi Catholic Diocese operates several community-based firms like Schools, Hospitals, and colleges. Such firms hire a large number of professional and unskilled laborers who are recruited from different angles of the country. Though the diocese has a large number of congregations in church sessions, however, it is not easier to recruit the best candidates from a single assortment. This causes complications and grateful competition once come to the issue of selecting the perfect candidate (Nkondola \& van Deuren, 2017). With the period of 5 years ago, we have witnessed even the government using many online systems including the employment portal to simplify the process of analyzing and processing employment applications hence 
achieving recruitment of better best employees. This study intends to examine the utilization of the erecruitment system on organization performance in MCDiocese. More still other religious organizations have been processing job applications through these systems, although not enough research has been done to determine their impact. This study targets viewing the utilization of e-recruitment systems in MCD. This study is based on exploring how the e-recruitment system has supported recruitment for Schools and Hospitals under Moshi Catholic Diocese.

\subsection{Research Objectives}

\subsubsection{General Research Objectives}

To assess the utilization of e-recruitment system on organizational performance in MCD

\subsubsection{Specific Research Objectives}

i. To find out the extent to which e-recruitment system has been successful in MCD

ii. To examine the benefits of e-recruitment system in MCD

iii. To assess the challenges of utilizing an e-recruitment system in MCD

\subsection{Research Question}

\subsubsection{General Research Question}

The main research question for this study was to what extent does the MCD succeeded in the utilization of the e-recruitment system.

\subsubsection{Specific Research Questions}

i. To what extent does MCD succeed in using the e-recruitment system?

ii. What are the benefits of the e-recruitment system to the human resources administration?

iii. What are the challenges encountered by the MCD recruitment panel in adopting an e-recruitment system?

\subsection{Hypotheses}

Ho: E-recruitment system has not been effective utilized by MCD.

H1: E-recruitment systems have been effectively utilized by MCD.

\subsection{Significance of the study}

The significance of this research work is the creation of a project that gives the concept of developing an online work-recruiting site to replace the old method of recruiting a candidate by generating various advertisements in papers. The key advantage is the creation of an online work site that provides an online framework for different organizations that helps to eradicate the manual recruitment process, cost savings, time-saving methods, and a straightforward framework. The seminar paper results are expected to shed some light on the private entities and religious-based institutions on the better strategies for using e-recruitment system is actively seeking out, finding, and hiring candidates for the potential vacancies. The success of this research work will further light on human resources experts outside and inside Tanzania on the importance of e-recruitment system in reducing the enlistment cost of new employees and simplification of analyzing applications through the best and reliable electronic techniques.

\subsection{Scope and Limitations of the Study}

Regarding the fact that the research has to be narrowed in all dimensions such as study topic and area coverage (Cohen \& Morrison, 2017). This research focused on the utilization of e-recruitment systems in MCD. The study involved recruitment practitioners in the MCD Schools and Hospitals found in Moshi Kilimanjaro. The study is expected to face a limitation on the understanding of e-recruitment terms among HR's since this is the new phenomenon to be established and utilized in MCD. However, to address these, the researcher tries at his level best to address the terms well to study participants to ensure that data collected are accurate in all dimensions (understanding of the questions asked and applicability of erecruitment as professional terms). 


\subsection{Theoretical Framework}

\subsubsection{Equity Theory}

Straw (1989) identified three levels of equal opportunity policies which include, equal opportunity as an equal chance that is non-discriminatory, equal access that is fair procedures, and an equal share that is outcomes and positive action. This equity approach should be implemented in a way to promote the organization by making it a favorable workplace for all future employees. This needs appropriate employment of a variety of strategies and policies. Assuming that the organizations of today are always dynamic, it is essential therefore to have employees that are willing to change, adapt to new ways of work, and always ready to learn new things.

This theory is used in this study as it enables the researcher to determine how the RCD formulate its erecruitment system as well as to what extent does this affects the whole recruitment process. The theory also enabled the study to determine the variables to be added in this study concerning institutions' decisions in formulating employment strategies and policies. Moreover, the study was able to scrutinize the association existing between employees and the applicability of those recruitment policies formulated by the institution.

\subsection{Conceptual Framework}

The utilization of the e-recruitment system in MCD can be attained through investigating the extent of adaption of e-recruitment system and benefits brought, the technological competence of the institution and staff who are the main implementers. In addition, all this cannot be reached without examining the influence of the institutional policies toward human management and decision-making strategies. Therefore based on those highlighted clues, this study had independent, dependent, and intervening variables that linked to each other based on the conceptual framework given in Figure 1.1

Figure 1.1 Conceptual Framework

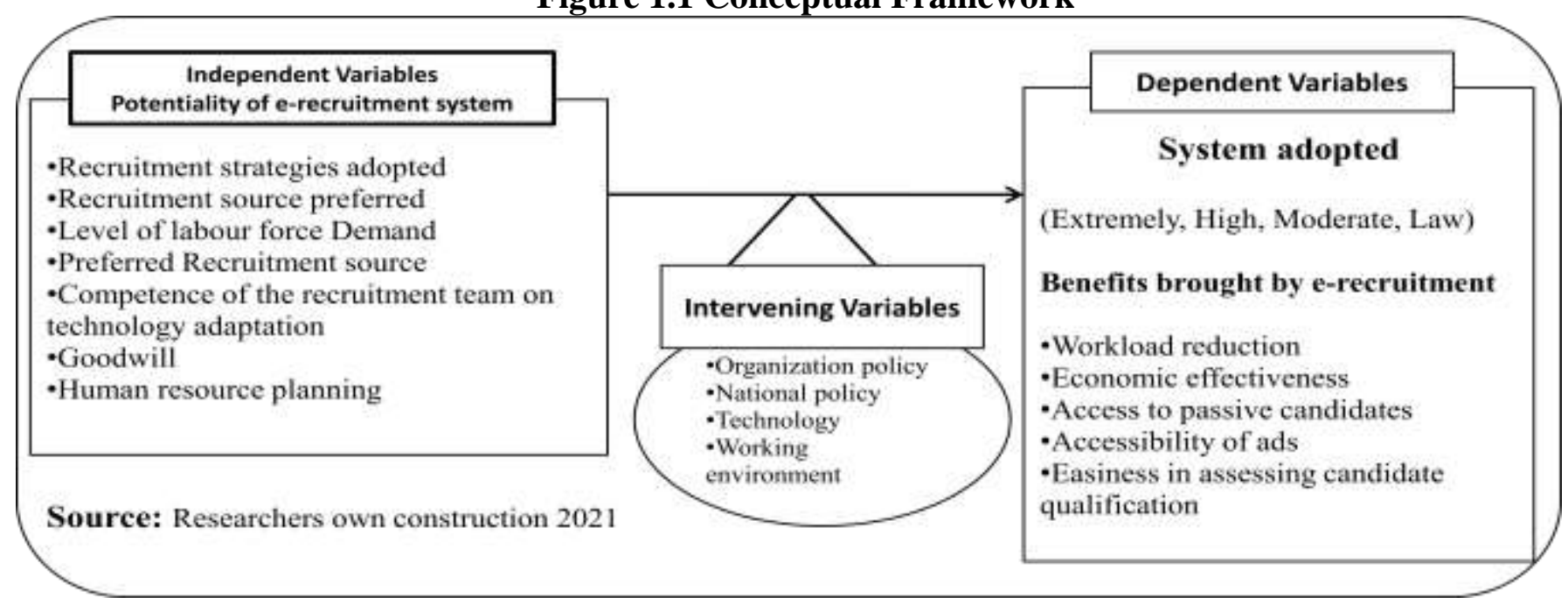

This diagrammatic illustration shows how variables of the study independent, dependent, and intervening variables interact to affect the study, therefore providing validity for it to be carried out. The illustration gives the relationship between the independent, which covers the recruitment strategies adopted, recruitment source preferred, and level of labor force demands, preferred recruitment sources, the competence of the recruitment team on technology adaptation, institutional goodwill, and human resources planning. The dependent variable is much relied on the longitudinal influence of the independent variable based on the study objectives. Having competent and well-trained staff facilitates the organization to overcome unnecessary expenses hence in addition increase productivity and maximize organizational profit. That's why in this study the researcher considered the extent of e-recruitment system adoption to rely on Likert scale items (extremely, highly, moderately, or lower) based on the extent to which the diocesan recruitment team utilizes the e-recruitment system. Moreover, the study sought to examine the benefits of e-recruitment adoption based on workload reduction, economic effectiveness, access to passive candidates, accessibility of advertised vacancy, and easiness in accessing candidate qualification or additional information. Moreover, the conceptual framework illustrated in Figure 1, gives the connection of intervening variables (organization policy, national policy, working environment, and technology) to the identified independent and dependent 
variables under investigation. This is because there is nothing in this world that can operate without the pressure of the surrounding environment (Macarthur, 2001).

\subsection{Operational Definition of Key Terms}

\subsubsection{E-recruitment system}

Refers to the approach used by the organization to obtain candidates for employment through the Internet, (Listwan 2010). The present scope of e-recruitment is variously estimated, depending on the sector, country, type of position being recruited for, and type of organization. In this study, the e-recruitment system referred to those approaches employed by the MCD in recruiting the employees via online sources like official Diocesan websites, e-mail, and other media.

\subsubsection{Staffing}

The staffing sector begins with human resource planning. Human resource planning intends to ensure that the organization has the long-term and short-term strategies in the overall organization's forecast, including the right type and amount of employees for the positions to support the success of the organization (DeCenzo; Robbins;\& Verhulst, 2013). In this study, the word staffing is used to refer to the planning prepared by the MCD human resource management to foresight what present and future personnel the organization needs.

\subsubsection{Selection}

Selection is the process of choosing the best-fit person for the role from the generated pool of qualified candidates (Bratton \& Gold, 2007). These two processes correspond with each other; without recruitment, there is no selection. In this study, the word selection is used to refer to the strategies used by the MCD human resource management to select the best candidate via online sources.

\subsection{Review Of Related Literature}

\subsection{Introduction}

This chapter presents the review of literature related to this study. It is divided into two major parts namely; conceptual and empirical reviews. The researcher examines critically other studies that have been conducted to this study and incorporates the findings obtained in this current study.

\subsection{Review of Theories}

Two theories, Technology Acceptance Model and the Objective theory guided the study.

\subsubsection{Technology Acceptance Model (TAM)}

The model was established by Devis (1986). The paradigm is one of the hypotheses of knowledge that describes how organizations should embrace and use technologies in their service. The theory holds that when a new device is introduced to consumers, different influences are affecting their decision to use it. According to this principle, operational productivity has not been increased until staff adopts the technology. The implementation of some advancement or in particular focused on information technology involves investment in computer-based tools to facilitate decision-making and contact planning. It is also very important that institutional choice and logic be defined for the programs. It is therefore important to consider that individuals can cope with technological improvements.

\subsubsection{Strength of the Theory}

Technology theory is based on two assumptions; the system's perceived usefulness; the value of equality, improved competitiveness, reliability and efficiency of operations, etc.; and the perceived ease of use of new technologies, such as ease of understanding, ease use or, easy control, and ease of remembering. This theory has clearly shown that there is a need for institutions and organizations to be ready to embrace digital transformation in their day-to-day operations to adapt to the growing economic climate dependent on new technologies to a large extent. 


\subsubsection{Weakness of the Theory}

The acceptance theory of technology has questionable heuristic meaning, limited interpretive and predictive ability, triviality, and no practical validity. Christophe, (2011)TAM, it is said, has diverted researchers' attention away from more pressing science challenges and generated an illusion of information acquisition performance. Furthermore, many scientists' autonomous efforts to expand TAM have confused as they try to adapt it to the relentless technological changes (Chesney, 2012). TAM has a flaw in all since reality has just relied on imagination. It also focuses on the real technology consumer, to explain whether a user perceives usability and without even a dispute, fails to elaborate the social structures and implementation (Yang et al., 2020).

\subsubsection{Applicability of the Theory}

Since the adoption and use of e-recruitment is a function of the user's perceptions about the method and its potential benefits, this theory is useful for the study. Furthermore, the organizations' use of e-recruitment is thought to be effective because it saves time and resources while also guaranteeing the best candidate for the role is found.

\subsubsection{Objective Theory}

The theory was advanced by Duval and Wicklund (1972). During the planning of the post definition, the principal places a strong focus on meeting the applicant's requirements. According to Duval and Wicklund, candidates use a very fair approach for deciding whether he/she should apply for the position or not, and if they do, do they seem to have a good opportunity of succeeding to be with the institution or firm. As a result, more detail is given to them, such as wages, employee compensation, and working environment, then the more the candidates would be able to consider these aggravating aspects and probably decide to pursue his/her carrier with the firm. This paradigm demonstrates the need for insightful advertising strategies aimed at attracting prospective applicants for a vacant position in a specific organization.

\subsubsection{Strength of the Theory}

The theory elaborated well about things to consider during the recruitment stage. That means the same thing if followed sequentially in the e-recruitment system benefit the respective institution by ensuring that it attain the same goal as expected in manual recruitment. Above all, the theory touches on both the employer and the employee. The theory has made it clear that while the employer is looking for an employee who can help the institution meet its goals, the employee needs more reliable work that focuses on his or her future.

\subsubsection{Weakness of the Theory}

The theory holds that an institution needs to focus on producing profits. The author believes that this is the prime target of any company for it to survive in the long term. However, that goal goes against the larger goals of religious institutions, which many do not exist after money. Most of these institutions, including the MCD, focused on the spiritual development of the community and more on helping the community by moving essential services to them.

\subsubsection{Applicability of the Theory}

The theory employed in this study enabled the study to assess and reveal the influence of the job specification on the e-recruitment and selection process. The study assessed the condition and procedures followed in the determination of the job specification and employee benefits that can be collected in the erecruitment portal to attract and enable the institution to get the best candidate. This goes perpendicular with the determination of the status of specified benefit attainability and examines to what extent does this affects the e-recruitment practice of an organization.

\subsection{Review of empirical studies}

\subsubsection{The utilization of e-recruitment system}

Meijer,s (2015)conducted a study in India on the utilization of e-recruitment. He further revealed that MNCs depend more on the Internet with the support of human resources teams. Most MNCs favor online recruiting through social media because it hits a large number of individuals at once. Pick profiles are attracted as a result and work is made easier to choose applicants from a wider pool. The use of E-technology and webbased sources for sourcing, scanning, filtering, and cross-examining candidates allows choosing the right 
candidate at a reduced cost and with less effort. The study was not well indicated the research methodologies used in conducting the study, for instance, the sample size was not well-formed some of the results were summing up differently. In the current study, the study ensured that the correct sample size is determined by using Yamane's (1967) sampling formula, in which one among the major parameters are population size and confidence level required.

Gronmo (2020)assessed the role of social media on the e-recruitment process based on existing literature. According to most prior studies, social media is employed as a secondary source of e-recruitment rather than as the primary one. Furthermore, it has been found that the use of social media as a complementary source is becoming more popular as a result of the low cost of information. Most profit-oriented companies relied on social Mediasin finding the best employees. However, the current study examined how social media as the part of the online sources assisted RCD to get the best employees

George (2017) in South Africa explored the strategies to be taken to increase the effectiveness of the recruitment and selection process in automobile industries in Cape-town province. The researcher employed a descriptive survey research design, Data was collected through in-depth personal interviews, whereby purposive sampling was employed to select a sample of 75 respondents. The study revealed that the government has to review labor laws and remove some of the conditions, which found to pull down the power of companies in employees selections basis on their demands. The study finds suggested that for effective recruitment and selection process the automobile industries must think about adopting the erecruitment system which helped to minimize over running recruitment costs and also widen the applicant market since it was easier to get the applicant from the wider areas in the country. Though the study was conducted in more than one automobile industry, the researcher did not indicate how many entities were involved and how many respondents were selected from each entity. In the current study, the study used a case study design and only staff who are involved in the recruitment process in Moshi Catholic Diocese.

Kamala (2019) researched Mwanza, Tanzania, on the efficacy of career portal and networking web recruitment. According to the results of the report, recruiters obtain applicants via career portals as well as personal recommendations. They compensated for referring those candidates, but if the applicant leaves the organization, the individual who referred the candidate must find a substitute. Employees are put under strain as a result of this. To stop a situation like this, job boards and networking pages lend a helping hand in this case. Finally, he makes several recommendations for HR to follow to improve their recruitment teams or working workers. Although technology is rapidly evolving, he agrees that the use of career portals and networking has its benefit. Recruiters must receive separate training to build good sites. The current study helped to determine if religious-based institutions like Catholic Dioceses are using career portals in recruitment and if so what are the gains that benefited from e-recruitment.

\subsubsection{The benefits of e-recruitment}

Van Doesum, (2016) researched the recruiting efficacy of career portals and social media platforms in Germany. He publishes actual photographs with workers of an organization in this report. In other words, the problems/issues that workers who serve in a recruiting unit face. Often multinational corporations hold online interviews to screen applicants. Recruiters, according to the author, find applicants through career platforms and personal recommendations. They compensated for referring those candidates, but if the applicant leaves the organization, the individual who referred the candidate must find a substitute. He finally, suggested some steps that they can take to improve their recruitment teams or working workers in this study. Although technology is rapidly evolving, he agrees that the use of career portals and networking, which is part of e-recruitment, has its benefit in human resources management. That is to say, Recruiters must receive separate training to build more sites and know how to use e-recruitment for the betterment of their institution. This study was conducted in well-developed nations, which have advanced multimedia and social media network, this influence the researcher to think about conducting the relevant study in Tanzania to see to what extent do e-recruitment system is adopted in religious-based institutions particularly the MCD.

Bogatova (2017) in Finland investigated the good approaches for improving the recruitment and selection process in private institutions. The study adopted both qualitative and quantitative approaches. Interview schedules, questionnaires, and focus group discussions were used for data collection. The study findings have shown that most of the interviewees emphasize companies adopt electronic recruitment systems, which is also able to perform preliminary selection process to reduce the burden of passing through a bulk of 
application letters. The study also found that HRs were also insisted to abide by their professional principles by ensuring that candidates got an equal chance of being selected unless otherwise the condition not meet. Concerning Tanzania the strategies adopted by the private sectors in reviewing and determining best candidates for the advertised job is not well investigated, therefore in this study, the researcher assessed how do religious-based institution particularly Moshi Catholic Dioceses are affected by the bulk set of applied candidates and if the e-recruitment system has assisted to deal with.

Irabor and Okolie (2017) conducted a study on the challenges associated with the e-recruitment system in Nigeria. The study involves $63 \mathrm{HR}$ 's from different private-owned institutions. The researcher used tools like questionnaires, and documentary review to collect data and finally analyzed through descriptive statistics. The study findings revealed that, despite its many advantages, the e-recruitment process has some drawbacks. As the result of an emerging trend in technology and process, also known as globalization, organizations should focus on the process to improve the superiority of their staff enlistment utilities. The study found that cost and time savings, an increased pool of candidates, and a worldwide catchment opportunity are all big advantages of using deep core ICT in recruitment. This study was centered on privately owned institutions that are profit-oriented. The current study was centered on the none-profit institution (Catholic Dioceses).

Innocent and Kalaskar (2016) examined the impact of the e-recruitment system on selected telecommunication companies' in Kigali Rwanda. The research included both qualitative and quantitative methods. Data were collected through interview schedules and questionnaires. The study revealed that Just as it is simple for a company to hire skilled individuals via the internet, it is also simple for competitors to hire the company's employees. Recruiters will seek out people who are good at what they do. Furthermore, many firms are eager to hire qualified candidates, and everything moves swiftly in the Internet world. This study involved telecommunication companies which are profit-oriented companies the current study assessed how religious-based institutions, particularly the Moshi Catholic Diocese, benefit from a large number of applicants and whether the e-recruitment system has helped to deal with this challenge.

\subsubsection{The obstacles for effective utilization of e-recruitment}

Pavitra (2018) examined the benefits and drawbacks of informal and traditional human resources management methods in hindering the implementation of the e-recruitment system process in Pakistan. The authors found that most of the administrators and persons who make the recruitment team were so rigid to adopt e-recruitment due to their benefits. One among the major claim was corruption and favoritism. However, the HR officers were declared that the E-recruitment is much cheaper than the traditional one in form of time and finances. This study revealed that the adaptation to e-recruitment has internal and external forces and one among the internal forces is the organizational culture and altitude of those who have to engage in the recruitment processes. By considering, the challenges noticed in this dissertation, the current study would consider the MCD by-laws and recruitment regulations as the intervening variable.

Chunguli (2003) conducted a study of one-recruitment practices among commercial banks in Kenya. The findings show that using the internet to recruit comes with it additional costs. Subscription fees are common on job boards, and establishing or extending a corporate Web site, as well as hiring people or outsourcing the monitoring and management of such sites, all cost money. The cost of management software for the recruitment process is also a factor. Keeping an Internet presence operational and current, as well as staying current with Internet technologies and business developments, is a crucial continuing experience. This study was conducted in Tanzania particularly in a religion-based institution (RCD) to see to what extent do they use online sources such as websites and recruitment portals to reduce recruitment workload and major costs incurred.

Oboi (2016)conducted a study on the influence of e-recruitment implementation on employee selection and recruitment at Kisii in Kenya. The study findings revealed that one of the most difficult aspects of online recruitment is establishing and maintaining a proximity relationship between the organization and the applicants. He claims that candidates believe there is no connection between themselves and the organization, which could be a competitive disadvantage, especially in this era of employee treatment that is more humanistic. This study involves employees from five hospitals only hence it was mostly bias on sample selection. The current study involved participants from schools, colleges, and hospitals all owned by the Catholic Diocese of Moshi. 
Rwezahura (2015) assessed the perceptions of human resources officers in plantation firms towards erecruitment in the Kilimanjaro region. The study was guided by human capital theory, the interactive paradigm used and quantitative research design, which was archived by analyzing the participant perceptions, attitudes, and understands knowledge, values, feelings, and experience. The study findings revealed that based on the nature of employees most of them are coming from the village areas in which internet access is a great challenge. Therefore $94 \%$ of the study participants declared that the e-recruitment system was not the best approach for recruitment in their industries unless were looking for the person to fill the professional positions. However, this study did not consider the role benefits brought with globalization in which most of the people nowadays own the smartphone include in the village areas whereby the information can easily spread out to the neighbors. Furthermore, the study did not examine effective strategies for addressing the problems that hinder recruitment and selection processes in plantation firms. This gap was captured in the current study in which despite examining the extent of implementation of erecruitment, the study also evaluated the obstacles and elucidation for the challenges.

\subsection{Research Design And Methodology \\ 3.1 Research Design}

A Research design is a strategy for planning and conducting a study (Cohen \& Morrison, 2017). The descriptive research design was employed to describe the approaches used by the MCD in utilizing the erecruitment system in MCD (Cohen et al., 2005). This design allowed the intensive study of a particular social unity over various variables but usually retain the unitary nature to collect enough data for concluding the population (Yin, 2017). This design is proposed based on the fact that; the study mainly focuses on examining the e-recruitment system in MCD institutions in which a variety of strategies have to be undertaken to establish well-organized facts and within the particular time interval.

\subsection{Targeted Population}

The study population is the aggregation of elements from which the sample is drawn (Erba et al., 2018). The study involved the Administrative of MCD. The study targeted MCD since the Diocese has well established administrative structure for monitoring all recruitment processes which makes it unique compared to others. The targeted population of this study comprised school Management teams. In addition, the study involved staff management from five Diocesan hospitals. Hence, the total population comprised 175 from Diocesan Schools and Hospitals.

\subsection{Description of Sample and Sampling Procedures}

According to (Creswell, 2014) a sample is a smaller and more accessible subset of the population that adequately represents the overall group, thus enabling one to give an accurate (within acceptable limits) picture of the population as a whole, concerning the particular aspects of interests of the study. The particular aspect of interest in this study is to examine the utilization of the e-recruitment system by MCD considering the ten schools and five Hospitals as a case study.

\subsubsection{Determination of Sample Size}

Bryman and Bell (2011) suggested the law of diminishing returns kicks whereby the researcher has to select the sample for the study based on time for conducting the study and cost for collecting the data. According to them as the cost exceeds the budget line, any additional respondents had additional errors to the information gathered hence make the study results to be non-representative to the targeted population. For precise results, Bryman and Bell recommended sample size of 30 to 50\% if the targeted population size is not exceeding 500individuals. Since the targeted population of this study is 175 , the researcher proposes to take $40 \%$ as the sample size which is equivalent to 70 participants. This sample comprised $40 \%$ of individuals from each targeted population category.

Table 3.1: Distribution of Sample Size

\begin{tabular}{|l|c|c|}
\hline Category (amount) & Target population Size & Sample size \\
\hline Diocesan Human Resource officers & 1 & 1 \\
\hline Hospital administrative & 30 & 12 \\
\hline School management associates & 45 & 18 \\
\hline
\end{tabular}




\begin{tabular}{|l|c|c|}
\hline school workers & 99 & 39 \\
\hline Total & 175 & 70 \\
\hline
\end{tabular}

Source: Researcher (2021)

\subsubsection{Sampling Procedures \\ 3.3.1.1 Stratified Sampling}

Stratified sampling is the sampling procedure in which the researcher split a population into homogeneous subpopulations called strata (plural of stratum) depending on specified features such as age, gender, race, or location (Mugenda, A., 2009). As to how addressed in Table 1, stratified sampling was used to determine the number of participants to be selected at the Hospitals and schools to reach the sample size indicated.

\subsubsection{Purposive Sampling}

The study employed purposive sampling to select Diocesan Human Resource officers, and heads of school from each school sampled. Purposive sampling is a type of non-probability sampling wherein the investigators identify segments of the population to engage in their study based according to their own decision (Almalki, 2016).

\subsubsection{Simple Random Sampling}

Simple random sampling is a sampling procedure in which each component in the population sample frame has an equal probability or equal chance of being chosen to participate in the study (Kothari, 2017). That is to say, to represent the whole data collection, a limited, random part of the entire population is used (Mugenda, A., 2009). The study used simple random probability sampling to select 12 hospital employees and 18 school management associates, 39 administrative associates, and 1 Diocesan human resource officers out of which a single individual was automatically sampled based on an administrative role, and lastly 12 hospital administrative staff. The researcher wrote the names of the school and hospital on a small piece of paper and put them in separate boxes for schools and hospitals. The researcher shooked the boxes well before peaking the number of papers required from each category. The name of the school and hospital which appeared on the paper peaked was sampled.

\subsection{Description of Data Collection Instruments}

This study proposed to use a questionnaire and interview to ensure that the study exhausted the effective utilization of the e-recruitment system of MCD.

\subsubsection{Structured Interview Guide}

An interview is a qualitative research methodology that entails asking open-ended questions to engage respondents and elicit information about a problem (Gronmo, 2020). In most contexts, the interviewer is a subject matter specialist who uses a well-planned and conducted sequence of questions to gain insight into participant views (Creswell, 2014). A structured interview guide was used to collect information from the key informers who are Diocesan Human Resource officers, procurators, and heads of schools and hospitals. This instrument enabled the researcher to have freedom of asking supplementary questions on the recruitment and selection procedures applied by the MCD including it is significant in obtaining competent employees.

\subsubsection{Self-Administered Questionnaire}

The questionnaire is a predefined series of questions used to collect data from individuals (Cohen, 2007). The questionnaire was used in this study because it enabled the researcher to obtain data that made it possible to describe the nature of the relationship existing between different variables in the study in a relatively short period. The researcher used this instrument to obtain data from School Management teams, Hospital Administrative officers and employees, School Workers, and the Diocesan Human resource officer. The questionnaires used had both open-ended and closed-ended questions relating to recruitment in which collectively helped to examine the utilization of the e-recruitment system in MCD. 


\subsection{Pilot Testing of Instruments}

A pilot study is an important part of any research undertaking. A pilot study refers to a small study to test research methods, data collection tools, sample recruitment strategies, and other research methodologies (Cohen \& Morrison, 2017). Before the implementation of a research project, a pilot study is undertaken to identify potential issue areas and inadequacies in the research instruments and methodology (Yin, 2017).In this study, the researcher conducted a one-week pilot study that comprised 22 individuals (equivalent to $20 \%$ of the study sample size). The participants peaked from the organs which had not been selected for actual study (un-sampled organs).

\subsection{Validity and Reliability of Research Instrument}

The test of Validity and reliability of this instrument was conducted to ensure data consistency before data analysis and presentation. The researcher used pre-tested to verify the consistency of the research instruments. The study applied the Cronbach's Alpha co-efficiency to measure the internal consistency of the research tool. The study also checked the validity of the research instrument by using research supervisors and three administrative staff from MCD in terms of language and content suitability for the study objectives before data collection started.

\subsection{Description of Data Collection Procedures}

During data collection, the researcher made an appointment with a key informant (Diocese Human Resources officer, procurator, and heads of schools) to be ensured for their availability. During the actual data collection, the researcher agreed with the interviewee to use a tape recorder. If the interviewee disagrees then the researcher used a notebook to record important responses during an analysis interview. Moreover, the researcher distributed questionnaires to the administrative heads of sampled schools and colleges as well as in each hospital and request them to respond to the question asked based on their best knowledge, understanding of the organization management concerning recruitment matters. Nevertheless, the researcher encouraged the participants who have to fill a questionnaire to communicate with him whenever they face any challenge regards to questions understanding. However, during the whole process of data collection, the researcher tried at his level best not to involve in influencing any kind of response from the participants.

\subsection{Description of Data Analysis Procedures}

The quantitative data was coded, cleaned, and analyzed based on descriptive and inferential statistical techniques. Statistical Package for Social Science package (SPSS) version 23 and Microsoft Excel employed for data cleaning and management. The researcher analyzed the data and presented it in form of a table and figures for more clarification. The researcher applied the chi-square test to assess the interdependence between dependents and independents variables. Furthermore, quantitative statistics are presented in the form of tables and graphs, while qualitative data is expressed in quotation form.

The qualitative data particularly from the open-ended questions and interview responses were summarized, coded, and analyzed in each theme/category and then relevant information was extracted, interpreted, and discussed for research objectives. Then, the researcher systematically goes through the data typically line by line to obtain the general idea of the information and to reflect on its overall meaning.

\subsection{Research Ethical Considerations}

The researcher got an approval letter to conduct this study from the Director of research and publications at Mwenge Catholic University (MWECAU). Thereafter, the research clearance was submitted to the Moshi Diocesan Human Resource officer requesting permission to conduct the study. Copies of permission letters were also submitted to each School and Hospital where the study took place. The researcher handled the information collected with a high level of privacy and confidentiality to ensure that no information leaks. Moreover, the researcher purposively explained the benefits of the study to the key informants and participants.

\section{Presentation, Interpretation, and Discussion \\ 4.0 Introduction}

This chapter address the presentation of findings regards to examine the utilization of e-recruitment system on organization performance: a case of Moshi Catholic Diocese (MCD) Furthermore, the chapter cover 
interpretation of presented results and its discussion concerning three research objectives (the extent to which e-recruitment system has been successful in MCD; the benefits of e-recruitment system in MCD and the challenges of utilizing e-recruitment system in MCD). As well as the findings concerning hypothesis (Erecruitment systems have been effectively utilized by MCD).

\subsection{Responses Return Rate}

The study is expected to involve 70 participants who are the part of school administrative team hence are familiar with general recruitment processes in their respective institutions (schools and hospitals). The participants were supposed to be sampled from primary and secondary schools owned by MCD. The results summarised in Table 5.1 show the return rate per each participant category involved.

Table 4.1 Participant Return Rate

\begin{tabular}{|l|c|c|c|}
\hline Category (amount) & Sample size & Returned & Return \% \\
\hline Diocesan Human Resource officers & 1 & 1 & 100 \\
\hline Hospital administrative & 12 & 12 & 100 \\
\hline School management associates & 18 & 18 & 100 \\
\hline school workers & 39 & 39 & 100 \\
\hline Total & 70 & 70 & 100 \\
\hline
\end{tabular}

Source: Field Data (2021)

\subsection{Demographic Information}

This part consists of the characteristics of participants based on their gender, education level, current position, and their working experience. Each variable is summarised in terms of frequency and percentages concerning each relevant attribute.

Table 4.2: Participants Demographic Characteristics

\begin{tabular}{|l|l|c|c|}
\hline Variables & Attributes & Frequency & Percent \\
\hline \multirow{4}{*}{ Gender } & Male & 32 & 45.7 \\
\cline { 2 - 4 } & Female & 38 & 54.3 \\
\cline { 2 - 4 } & Primary & - & - \\
\cline { 2 - 4 } & Secondary & - & - \\
\cline { 2 - 4 } & Diploma & 9 & 87.1 \\
\cline { 2 - 4 } & Degree & 61 & 27.1 \\
\hline Working Experience & Less than 5 & 19 & 54.3 \\
\cline { 2 - 4 } & 5 to 10 & 38 & 18.6 \\
\cline { 2 - 4 } & Above 10 & 13 & 12.9 \\
\hline
\end{tabular}

Source: Field Data (2021)

\subsubsection{Gender}

The results in table 4.2 show that $54.3 \%$ of participants were female and 45.7 were male. This indicated that the distribution of administration in institutions under the Roma Catholic Diocese is uniformly distributed concerning gender. That is to say, there was no gender-based in offering the administrative role. Therefore concerning these findings, it is still revealed that responses addressed in this dissertation are free from gender bias.

\subsubsection{Education Level}

As staffs in higher management rank considered during sampling the results presented in Table 4.2 indicated that out of all 70 participants involved none of them had primary or secondary certificate as the higher education level. About $87.1 \%$ of respondents had a degree and $12.9 \%$ diploma level. Those with degree levels include participants with bachelor's degrees and masters. These findings imply that the participants 
were good from an academic perspective since most people end up with a degree. According to Belisar and Appolloni (2020), education plays a significant role in impacting intellectual skills to the people and interconnect the person with multicultural dimensions that assist to wide a thinking and reasoning ability. However, having well-educated staff gives the room for the institutions to witness unforeseen outcomes earlier and makes the positive decision as soon as possible so that it could be a part of celebrating populaces in upcoming days. Investing in e-recruitment needs well-trained staff and people with the willingness and ability to implement.

\subsubsection{Working experience}

The results on working experience show that $54.3 \%$ of participants sampled had a working experience of 5 to 10 years while the rest $27.1 \%$ have been working for less than 5 years in the current positions and other $18.6 \%$ have been working for more than 10 years. This implies that the participants who were involved in this study had working experience for the interval of 5 to 10 years as shown in table 4.2. Therefore, their participation in this study added a vigorous part in getting reliable results. According to Chunguli (2003), working experience is the most full important thing required by any employer as it reveals the true ability of the person to do an actual thing than basing on theoretical perspectives. With regards to Erba et al, (2018) working experience gives greater self-awareness, maturity, independence, and self-assurance Gronmo (2020)argued that 'we change as you grow, we develop, and gain new experiences. Knowledge, skills, interests, and even values and personality may evolve. Because everything changes, so do a perspective on ourselves and the world around us. With regards to Irabor and Okolie (2017), we cannot expect the decisions we make today to be appropriate for the rest of our life. Therefore through examination of the working experience of participants involved in this study, it assured that most of the participants involved in this study had a strong familiarity with organization management and the impact of different actions taken in recruitment concerning the outcomes expected. Their participation in this study gives room to the study to be assured that the response obtained from them is almost what was required for the completion of the objectives stated.

\subsection{The Extent of Using E-recruitment System}

In this objective, the researcher sought to examine the extent to which Moshi Catholic Diocese uses an erecruitment system in acquiring new employees in their respective Schools and Hospitals. The data collected from the administrative staff (heads of Schools and Hospitals and academic teachers that relate to this objective have been analyzed using percentages then presented in form of figures (Figure 4.1). Moreover, the results from the Diocesan Human Resource Officer (HR) were presented within relevant administrative responses in the quotation form.

\section{Figure 4.1. Participants Responses on the Recruitment Source and Mode of Application used}

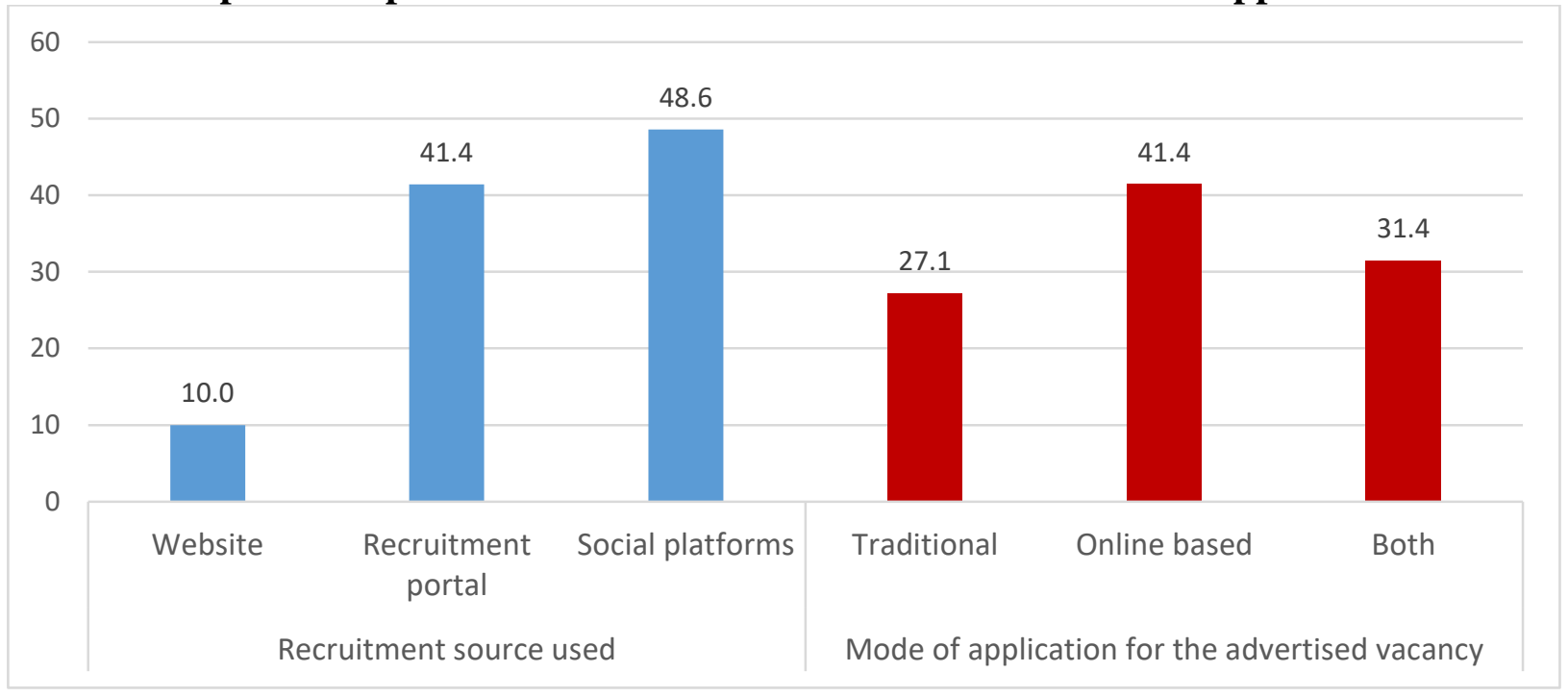

Source: Field (2021) 


\subsubsection{Recruitment source used}

Concerning the findings summarised in Figure 4.1, it has been revealed that the Moshi Catholic Diocese uses a website, recruitment portal, and social media platforms such (LinkedIn, WhatsApp groups, Facebook, and others) to promote the free vacancies in their respective Schools and Hospitals. The findings show that Social Medias (48.6\%) and recruitment portals (41.4\%) are highly used compared to websites $(10 \%)$. One of the school heads argued that,

"Given the current state of technology, a large percentage of educated people use smartphones and I am a major customer of social media. This facilitates the dissemination of information rather than the use of newspapers, posters or advertisements in places with social gatherings such as churches and so on."

These responses reveal a greater reason for many employers to use e-recruitment systems than traditional methods as described by Fred and Kinange (2018).In this study, it was found that most job advertisements spread faster through social Media than even the websites of the organization concerned. The rapidity of disseminating information through social media has made these networks important in not only connecting people but also in meeting people and their future employers.

\subsubsection{Mode of Application used}

Apart from the issue of dissemination of employment information to be able to find qualified applicants promptly, the issue of the method of submitting employment applications is even more important. This is because one can meet the job advertisement and he/she possesses all the qualifications to get the position but fail to apply due to various challenges such as distance, lack of funds to cover application costs, or even difficulty accessing the prescribed application methods. This study revealed that Moshi Catholic Diocese is mostly using online application methods $(41.4 \%)$ for the advertised vacancies than traditional methods $(27.1 \%)$. About the findings presented in Figure 4.1, it has been revealed that the diocesan recruitment team does not ignore the contribution of traditional methods that is why it does not limit those who are willing to use conventional methods such as writing applications and submitting them directly to the employer using such systems. This helps the institution to have a wider scope to find prospective staff in various fields in Schools and Hospitals under the diocese. These results are directly related to Dhamija (2012) who found that using a variety of ways to receive job applications allows the institution to find productive employees on time. Ahmad (2013), who disclosed that nearly 55\% of human resource officers in the reviewed organizations use the internet to look for prospective employees via social media platforms such as Facebook, WhatsApp groups, and LinkedIn. However, Mohammed (2013) indicated that the key success elements of e-recruitment include the value-added services given by job sites, cost-effectiveness, speed, offering customized solutions, assisting in the establishment of relationships with HR managers, and facilitating company brand promotion.

virtually no institution uses e-recruitment one hundred percent (George, 2014). According to a study conducted by Lipumba (2018), it has been shown that many public and private organizations use erecruitment at certain stages such as advertising vacancies, receiving applications, conducting preliminary screening, and sometimes conducting interviews online systems. But more than that it was proven that these institutions still carry out some recruitment processes using traditional methods especially in conducting intensive candidate selection and enlisting.

\subsubsection{Recruitment Method used for the Recently Three Years}

Hiring strategies are always changing, and the Internet has dramatically altered the scene in recent years. Globally, a significant number of academics and scholars have been working around the clock to analyze and improve the effectiveness of recruiting policies and procedures. The findings discovered in this study as summarized in Figure 4.2 shows that the internet, recruitment agency, and executive searcher are the most common recruitment methods used by MCD in recent three years. 
Figure 4.2 Recruitment method used for the recently 3 years in percent

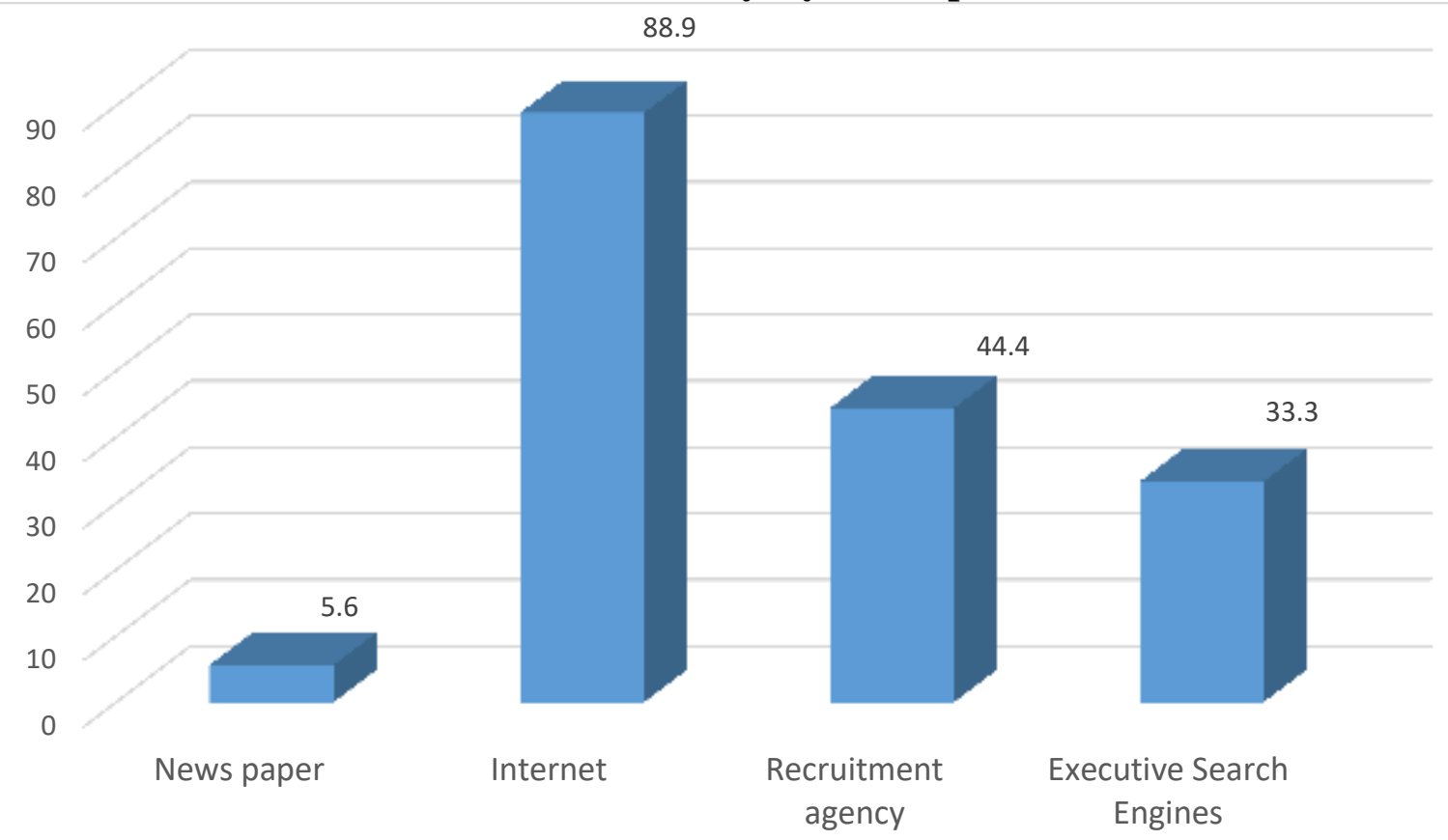

Source: Field Data (2021)

The study findings had also indicated that, during the last 3 years, $88.9 \%$ of the participants involved agreed that the MCD used the internet for recruitment while $44.4 \%$ had also used recruitment agencies. However, most of the recruitment agencies are also using online sources in searching for the job seekers like social Media, websites, and recruitment platforms. This conclusion is consistent with the findings of Millar et al. (2015), who found that 96.2 percent of employers polled utilize social networking sites such as Google and other social networking sites to do background checks on potential job applicants. The findings presented by Reis and Melão (2020) indicated that about $40 \%$ of the United Kingdom enterprises employ recruitment agencies to assist in recruiting issues while $39 \%$ currently utilize a combination of in-house and outsourced techniques.

Furthermore, Ccareerbuilder.com performed a poll that revealed that $67.3 \%$ of Human Resource Managers had utilized social networking sites to evaluate potential workers, which is a smaller number than the aforementioned findings in figure 4.2. Employers are becoming more aware of social networking sites in general, and the data herein show that MCD has begun to use these resources as part of its hiring tools. Staying proactive on social media platforms like Twitter helps Recruiters to 'reach' potential prospects in a variety of ways like (shared connections and common conversation topics. Furthermore, it makes it easier for job searchers to contact. Using social media, recruiters may not only contact a far larger number of individuals but also identify professionals with the qualifications they need. Traditional recruitment tactics, such as job boards or advertising, typically involve only active applicants who are actively seeking such information. 
Figure 4.3: Participant Response on Preferable Recruitment Tools byMCD

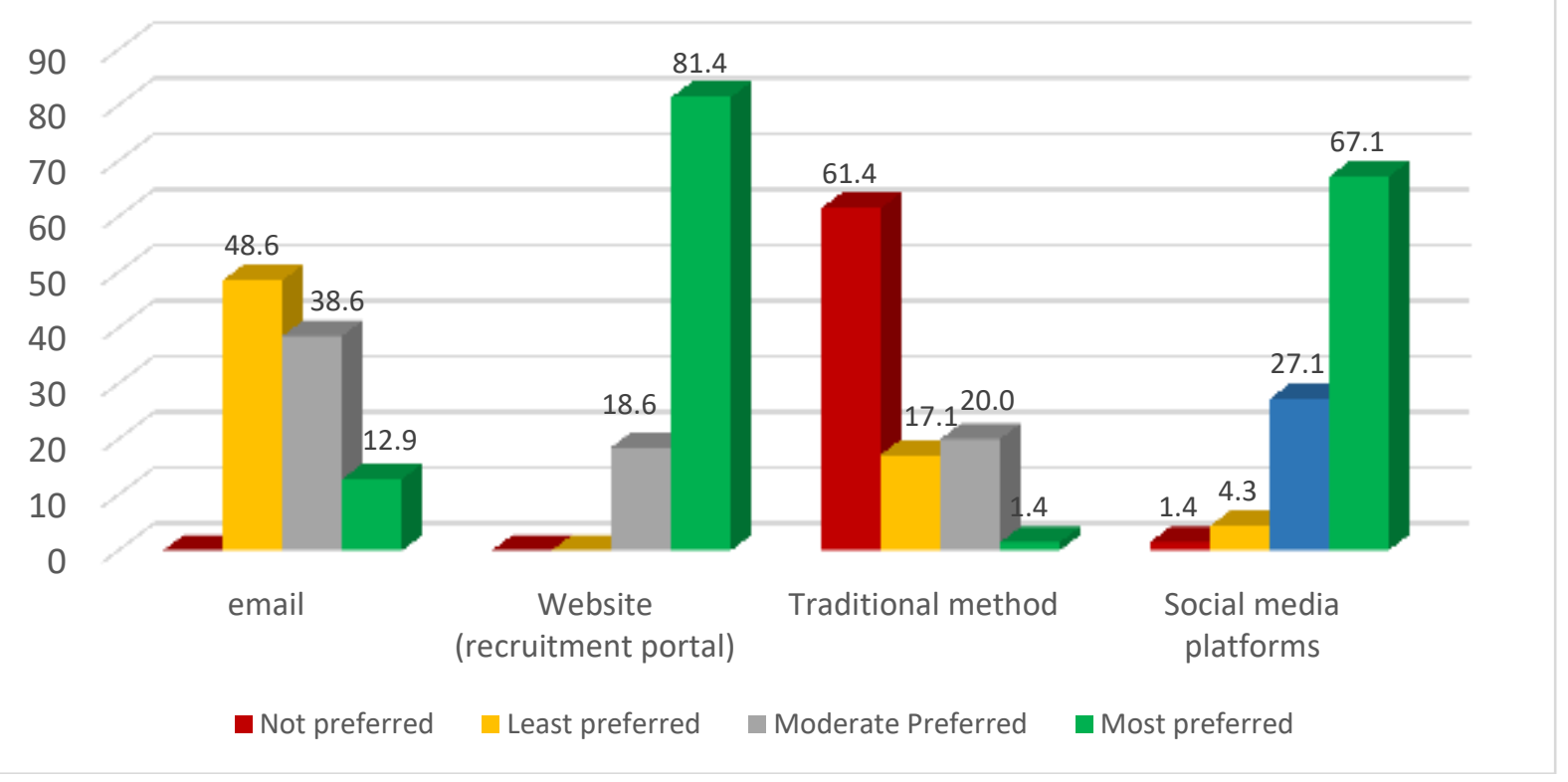

Source: Field (2021)

\subsubsection{Preference E-mail}

Through the results in Figure 4.3, this study found that Moshi Catholic Diocese uses e-mails to receive job applications, although this system is used to at least an extent of $48.6 \%$. Moreover, 38.6 percent of the participants in this study, all of whom were senior administrators of the entire school and hospital system, acknowledged that email is moderately preferred while $12.9 \%$ mostly preferred to use email. These results show that the e-mail system sending job applications is popular and also used in receiving job applications in various advertised positions in Schools and Hospitals under the Moshi Catholic Diocese although not to a large extent. There have been many challenges preventing many institutions from using the email system such as the presence of spam viruses and data storage. One of the school heads argued that,

"Unless you install a firewall and anti-spam software, unsolicited email might overwhelm your email system. Other difficulties with internet and email security may occur, especially if you use the cloud or remote access."

In the research conducted by Kaur (2015) he found that an email can go to the wrong person accidentally, hence potentially leaking confidential data and sensitive business information can leak out. Despite that, it is still suggested that, before approaching a passive applicant, find out what motivates them and what makes them apply in the current position. Using this information, tailor your sourcing emails to describe what you can provide them rather than what they can do for your firm.

\subsubsection{Preference for Recruitment Portal}

A career (recruitment) portal, often known as a job board, assists applicants in finding jobs and businesses in their search for prospective candidates. Job portals are the quickest way for employers to post job openings and job seekers to find them. In other terms, it is a website where companies can advertise job opportunities and job seekers may post their abilities. The findings presented in Figure 4.3 show that most of the participants agreed that the recruitment portals were mostly preferred $(81.4 \%)$. It's only $18.6 \%$ indicated a moderate preference for recruitment portals while none of the participants shows the least interest in recruitment portals. These findings collide with Skerfving (2016) who revealed that this system (recruitment portals) greatly simplifies the task of simplicity. It is easier to collect information and once available you can immerse it directly in excel and perform feasibility studies until you find the right employee. Through this research, it has been found that the e-recruitment system is more closely related to the use of recruitment portals which increases the efficiency of application and even filters candidates to find the right person for the job advertised.

\subsubsection{Preference for Social Media's}


In line with the usage of email and career portals, Social Media platforms are also not left behind. The results of this study show that 67.1 percent prefer the usage of a social media platform to be used in sending job applications. This system was supported at least by $27.1 \%$ of partners with $1.4 \%$ rejecting it. One of the staff at these institutions admitted saying that,

"The growth of technology has now led to Social Media such as Face book and LinkedIn being used for recruitment due to the creation of recruitment pages systems that are easier to find staff due to a large number of users of these platforms".

Social networking is not a novel technique for recruiting. With the surge in popularity of LinkedIn, Twitter, and Facebook in recent years, you may expect a big number of recruiters and HR professionals to use them for recruitment advertising. Social networking is an excellent tool for reaching out to that sought-after pool of potential applicants who aren't actively looking for a new job but would be willing to change if the appropriate opportunity presented itself. Other social media methods, like Twitter hashtags, or asking any workers who currently work in a comparable function to share the vacancy with their connections, can also be used to reach the prospective employees.

In a study conducted by Melanthiou and Constantine (2015), it was found that although many employers have had a negative attitude towards the use of social networks, basically these networks have a lot of benefits in the whole issue of finding productive employees due to the large wave of young people using it.

\subsection{The benefits of e-recruitment system}

In this objective, the study thought to examine the benefits gained by the Moshi Catholic Diocese recruitment team after implementing e-recruitment methods. The responses gathered from the study participants who are the part and parcel of the diocesan recruitment board were coded, effectively cleaned, and analyzed in form of frequencies, percentages, mean and standard deviations. The researcher presented the summary of the findings in form of tables (Table 4.3, Table 4.4).

Table 4.3 Participants Perceptions toward the Cost Analysis in Using E-recruitment

\begin{tabular}{|l|cc|c|c|c|c|c|c|c|c|}
\hline \multirow{2}{*}{ Variable } & \multicolumn{2}{|c|}{ Less costly } & \multicolumn{2}{c|}{ Equally } & \multicolumn{2}{c|}{ costly } & \multicolumn{2}{c|}{ High costly } & \multirow{2}{*}{ Mean } & \multirow{2}{*}{ STD } \\
\cline { 2 - 14 } & $\mathrm{f}$ & $\%$ & $\mathrm{f}$ & $\%$ & $\mathrm{~F}$ & $\%$ & $\mathrm{~F}$ & $\%$ & & \\
\hline Advertising & 45 & 64.3 & 19 & 27.1 & 4 & 5.7 & 2 & 2.9 & 1.47 & .737 \\
\hline Selection & 16 & 22.9 & 44 & 62.9 & 8 & 11.4 & 2 & 2.9 & 1.94 & .679 \\
\hline Enlisting & 48 & 68.6 & 18 & 25.7 & 2 & 2.9 & 2 & 2.9 & 1.40 & .689 \\
\hline Conducting & 24 & 34.3 & 26 & 37.1 & 7 & 10 & 13 & 18.6 & 2.13 & 1.089 \\
\hline
\end{tabular}

Source: Field (2021)

\subsubsection{E-recruitment Expenses in Advertising}

The study findings as summarised in Table 4.3 indicate that $64.3 \%$ of the participants involved in this study, agreed that e-recruitment is economically effective as it uses fewer expenses in advertising compared to traditional approaches. In addition to this $27.1 \%$ argued that the expenses of advertisement are the same for traditional and modern recruitment approaches while only 5.7 said that the e-recruitment system is costly and $2.9 \%$ declared that it is highly costly. Concerning these findings, the Diocesan HR argued that,

"You can't compare the cost of advertising jobs through online sources and other systems. Online sources are cheaper and easier to use because they do not have many limitations. Advertise a job advertisement in a newspaper you pay per square meter while on radio or television stations you pay for hours. When using your Facebook page, Twitter, or LinkedIn there are no deductions for that system unless you have decided to promote ads where the cost starts from lusd for the whole day i.e. 24hrs".

These findings are parallel with Holm (2014) who reported that some social networking features cost money. Paid advertising, such as LinkedIn Job Posts and Job Slots, as well as a recruiter license, have a cost. However, it is free to post your job openings on your LinkedIn company page, Twitter, or Facebook. In addition to this, the organization can use its social media profiles to take advantage of free advertisement.

\subsubsection{E-recruitment Expenses in Selection}

After job advertisements are advertised by qualified people to apply what follows is a selection to get one to fill the advertised soul. In this study, it was found that almost half of the participants $(62.9 \%)$ said that the 
cost of analysis to find a qualified applicant is not very different from traditional methods. This is due to the process being done through an individual profile and to determine if he or she deserves the position. However, these findings are not in line with other researchers where according to a study conducted by Belisari (2020) it was found that e-recruitment is very helpful in the whole issue of selection as screening begins at the first stage of job creation by blocking unqualified people. Mentioned inability to submit their application. Plus. Faliagka, Tsakalidis, and Tzimas (2012) added that e-recruitment simplifies the whole process of preparing data in an excel sheet and thus provides it quick analyst in the whole process of finding a productive applicant for a company or institution. You can analyze a candidate's skills, previous experience, and personal traits when evaluating their application. You cannot, however, check for alignment with your company's culture and principles. This is where the social media audit takes place.

\subsubsection{E-recruitment Expenses in Enlisting}

In the process of declaring eligible applicants for simplification, the results of this study showed that a large percentage of respondents $(68.6 \%)$ admitted that e-recruitment is easier than traditional approaches. one of the participants added that,

"By e-recruitment, only one ad can be prepared and posted on social media. The information will spread quickly to reach the people closest to the person who often informs them and arrive early for convenience." A study conducted by Meijer (2015) showed that it is easy to notify the applicant through the same platform because his information is directly on his job application something that is not easy in traditional methods. Despite social media, there is a great deal of flexibility to notify the applicant by email or through the career portal he used to apply for the job. So the presence of many alternatives ways to reach a competent creator makes this method easier and cheaper compared to traditional methods.

Table 4.4 Benefits Brought by E-recruitment Compared to other Sources

\begin{tabular}{|l|c|c|c|c|c|c|c|}
\hline Variable & SD & D & N & A & SA & Mean & STD \\
\hline $\begin{array}{l}\text { Access to } \\
\text { vacancies 24 hours } \\
\text { a day }\end{array}$ & - & $\begin{array}{c}9 \\
(12.9)\end{array}$ & $6(8.6)$ & $\begin{array}{c}19 \\
(27.1)\end{array}$ & $36(51.4)$ & 4.17 & 1.049 \\
\hline $\begin{array}{l}\text { online recruitment } \\
\text { is affordable }\end{array}$ & $6(8.6)$ & $4(5.7)$ & $5(7.1)$ & $\begin{array}{c}34 \\
(48.6)\end{array}$ & $21(30)$ & 3.86 & 1.171 \\
\hline $\begin{array}{l}\text { Online recruitment } \\
\text { is easy }\end{array}$ & $2(2.9)$ & $4(5.7)$ & $7(10)$ & $\begin{array}{c}29 \\
(41.4)\end{array}$ & $28(40)$ & 4.1 & 0.995 \\
\hline $\begin{array}{l}\text { Shorten hiring } \\
\text { process }\end{array}$ & $6(8.6)$ & $4(5.7)$ & $\begin{array}{c}12 \\
(17.1)\end{array}$ & $\begin{array}{c}29 \\
(41.4)\end{array}$ & $19(27.1)$ & 3.73 & 1.179 \\
\hline $\begin{array}{l}\text { Broader scope for } \\
\text { candidates }\end{array}$ & - & $\begin{array}{c}9 \\
(12.9)\end{array}$ & $6(8.6)$ & $\begin{array}{c}26 \\
(37.1)\end{array}$ & $29(41.4)$ & 4.07 & 1.012 \\
\hline
\end{tabular}

Source: Field (2021)

\subsubsection{Accessibility}

The results are in Table 4.4. show that a large percentage of participants admitted that e-recruitment has helped the job advertisement to be open for more than 24 hours a day and thus provide a broad space for anyone qualified to apply (mean $=4.17$ ). while $12.9 \%$ disagreed that e-recruitment is not accessible all the time before the deadline, $27.1 \%$ agreed and $51.4 \%$ strongly agreed. These findings have also shown that erecruitment reaches more people more quickly and easily than traditional methods (mean $=4.07$ ). This still revealed that e-recruitment is most full advantageous to the MCD in form of accessibility of the advertised vacancies than traditional methods. The findings collided with Tambe (2019)who argued that through erecruitment job postings and campaigns can be distributed via numerous social media channels to a specified target demographic. This gives room for the recruitment team to reduce the workload of having a huge bundle of applications that don't have the required qualifications.

\subsubsection{Affordability}

With regards to the findings addressed in table 4.4, it has been revealed that e-recruitment is more affordable than any other recruitment method based on cost and time effectiveness in processing job applications and 
reviewing candidates' qualifications. The findings show that Only $14.3 \%$ disagreed that e-recruitment is affordable while $7.1 \%$ had neither agreed nor disagreed. However, the findings still show that $78.6 \%$ of participants involved declared that e-recruitment is the most affordable recruitment mode. The findings from one of the schools' management associates argued that,

"e-recruitment enables us to obtain more information about the applicant through his or her social media. we take a closer look at his past and recent posts, the people who have to follow, the types of posts he likes or shares. This further helps you to be satisfied with his overall dynamics".

This is consistent with the works of literature studied by Kaur (2015), which revealed that e-recruitment has a great benefit in time savings as it takes a short time interval to see its impact hence play a role in fulfilling the emergence vacancies that need to be filled urgently. Holm (2014) had also argued that Online job advertising may be posted in a matter of minutes and quickly shared on a variety of social media platforms with no effort.

\subsubsection{Conductibility}

In addition, $81.4 \%$ have acknowledged that e-recruitment is much easier to coordinate compared to traditional recruitment which consumes a lot of resources such as money, time, and so on and thus adds more work to process applications. The finding addressed in Table 4.4 shows that $41.4 \%$ of the participants agreed that e-recruitment is easy as well as $40 \%$ shows strong agreement on the same item. In addition, the participants had also agreed that e-recruitment has shortened the hiring process compare to traditional methods. One of the hospital management associates argued that;

"It is not difficult to learn how to utilize an e-recruitment system. it is simple to use and provides a platform for all HR managers to monitor the hiring process. Furthermore, the cloud-based functionality enables the company to have an unlimited CV database."

Filtering features in e-recruitment systems assist recruiters in locating excellent applicants with capabilities that fit the job opening. As a result, the filtration capabilities provided by e-recruitment technologies expedite the process of sifting applicants based on experience, training, skills, and a variety of other factors.

\subsection{Challenges Associated with E-recruitment under MCD}

In this objective, the researcher sought to examine the challenges encountered by MCD in the implementation of e-recruitment. The findings were obtained from open-ended questions and interviews. During analysis, the responses from each participant were grouped based on the common themes, and the frequency of each relevant response was calculated as well as its percentage.

Table 4.5Challenges Encountered in Using E-recruitment method

\begin{tabular}{|c|c|c|c|}
\hline Variable & Attributes & Frequency & Percent \\
\hline \multirow{6}{*}{$\begin{array}{l}\text { Advertisment } \\
\text { challenges }\end{array}$} & Attracting the right candidates & 32 & 45.7 \\
\hline & Navigating online recruiting tools & 33 & 47.1 \\
\hline & Technology Issues & 39 & 55.7 \\
\hline & Limited creativity in poster design & 35 & 50.0 \\
\hline & attracts fraudulent applicants & 45 & 64.3 \\
\hline & You may miss out on great employees & 34 & 48.6 \\
\hline \multirow{4}{*}{$\begin{array}{l}\text { Challenges in } \\
\text { Enlisting Selected } \\
\text { Applicants }\end{array}$} & High Volume of Responses & 34 & 48.6 \\
\hline & Too many irrelevant or underqualified applicants & 33 & 47.1 \\
\hline & Ghosting & 36 & 51.4 \\
\hline & Passive candidates & 33 & 47.1 \\
\hline \multirow{2}{*}{$\begin{array}{l}\text { Challenges in } \\
\text { Interviewing the } \\
\text { Candidates }\end{array}$} & Connectivity problems can arise, & 31 & 44.3 \\
\hline & $\begin{array}{l}\text { Candidates must have access to a computer or } \\
\text { internet. }\end{array}$ & 37 & 52.9 \\
\hline
\end{tabular}




\begin{tabular}{|l|l|c|c|}
\hline & Delays can occur in transmission across the internet & 29 & 41.4 \\
& Building rapport & 41 & 58.6 \\
\hline
\end{tabular}

Source: Field (2021)

\subsubsection{Advertisment Challenges}

One of the most significant drawbacks of online recruiting is the overabundance of unqualified applications. You may waste a lot of time going through applications if you don't have recruitment software that integrates with one of the supreme applicant tracking systems. With respect to the findings addressed in table 4.5 , it has been revealed that there are several challenges faced by MCD in using e-recruitment particularly in an advertisement of the empty vacancies. The findings show that $45.7 \%$ of the candidates involved in the study argued that the MCD faces a major challenge in finding qualified job applicants from the pool of unemployed youth. The Diocesan human resource officer argued that;

"Depending on the speed of the application, most young people apply when we advertise for a position but only a few of them have the required qualifications. This gives us a very big challenge in terms of analyzing until we find the one we need."

In addition, most of the participants declared the technology to be a great challenge particularly in processing advertisement posters and posting in different recruitment sources. $47.1 \%$ arguing that they face a challenge in navigating through recruitment platforms due to limited skills and experience with online pages while $55.7 \%$ argued that they face hardship to cope with technology particularly in recruitment processes. Receiving huge numbers of applications requires extra time to prune. Sometimes it causes technological difficulties with the platform being used, and the job ads themselves have to be modified regularly, so the process may become tough to handle. This diverts the recruiting team's attention away from other work aspects as it requires close monitoring.

Despite the technological limitations, the study had also revealed that online recruitment is faced with fraudulent applicants as replied by almost $64.3 \%$ of the involved participants. One of the school management associates argued that "Some applications may be forged to get information about the organization or hiring officer. Likewise, spammers may exploit the information put online to sell a service or product to an organization."These findings collide with Thomas (2019) who argued that if you reveal too many details in online advertisement, dangerous hackers may be able to exploit the information to possibly get access to institutional IT systems.

\subsubsection{Challenges Associated with Selection and Enlisting}

With regards to the selection and enlisting of the selected candidates, the study revealed that there are some challenges faced by MCD particularly 'ghosting' which was indicated by $51.4 \%$ of the candidates involved in this study. More than half of MCD management associates reported being "ghosted" by applicants who either do not show up for interview appointments or do not react to their correspondence. This is hardly unexpected given that the current employment market provides job searchers more flexibility in deciding which chances to pursue and when. Applicants believe that skipping an interview or sending a recruiter directly to voicemail has no consequence. Nevertheless, for the company, applicant distortion is inconvenient, wastes important resources, and can severely delay the recruiting process.

Moreover, $47.1 \%$ of the participants argued that the MCD recruitment team is facing too many irrelevant or underqualified applicants. One of the management associates argued that;

"Some people fail to submit accurate information online because they are not computer literate. They are prone to making errors such as incorrectly filling out their name, native location, credentials, and so on."

In addition, the diocesan HR added that;

"Online resumes are often copied, increasing the likelihood of overlooking genuine prospects. Because resumes are submitted online, there is no guarantee of the validity or veracity of the information given."

These findings revealed that most of the applicants are not familiar with how to use electronic equipment that is used for e-recruitment or are not serious in ensuring that their applications are free from error so that to get a higher likelihood of being enlisted for an interview and finally win for the job. The findings are relevant to what was reported by Rwezahura (2015) that, making a critical error, such as submitting the wrong cover letter to a prospective employer or misspelling an organization's details, is not something to 
chuckle about. Sending the incorrect job application might result in being dismissed as a prospect since the recruiter may believe that a candidate is an irrational person who is unprepared for occupation.

\subsubsection{Challenges Associated with Interviewing}

The study pays close attention to interviews and questionnaires findings concerning the challenges associated with interviewing candidates through online platforms. Despite the great technological innovation reached in the world particularly during this pandemic (Covid-19), the study revealed that the MCD faced several challenges in interviewing the applicant through online sources. About $52.9 \%$ of the interviewed candidates revealed that internet access is the most drawbacks faced as the candidate must have access to a computer and strong internet access to facilitate the online interview. In addition to this, poor internet connection had led to unexpected disruption during an interview while other times they fail at all to proceed due to severely low connection.

Moreover, the study findings had also indicated that about $58.6 \%$ of the participants reported that online interview is failing to build the required rapport. The internet recruitment process consists of emails and maybe phone interviews, which might be perceived as too impersonal. It is difficult to establish if the candidate will be a good match for the institution and its culture if the employer does not have the opportunity to do several in-person interviews. The candidate may also have difficulty determining whether the institution is a good fit for her. Such limitation forces the MCD to conduct some interviews physically by requesting the enlisted candidates to attend physically

These findings collided with Chesney (2012) who reported that Scheduling online interviews may prove to be a tremendous task for recruiters. The delay in interview scheduling implies that the employment position will remain empty for a longer length of time, which is bad for institutional productivity. 


\section{Summary, Conclusion, and Recommendation}

\subsection{Introduction}

This chapter shows the summary of the whole study, conclusions, and recommendations. The first part comprises a summary of the whole study, followed by conclusions and recommendations

\subsection{Summary}

\subsubsection{Summary of the Study}

This study was conducted to assess the utilization of an e-recruitment system on organizational performance in the Moshi Catholic Diocese, Kilimanjaro, Tanzania. The study was guided by three major research objectives that are; the extent to which the e-recruitment system has been successful in MCD; the benefits of the e-recruitment system in MCD and the challenges of utilizing e-recruitment system in MCD. The study involved $70 \mathrm{MCD}$ management associates from primary schools, secondary schools, and hospitals under MCD in Kilimanjaro through interviews and questionnaires. The study was guided by Technology Acceptance Model propagated by Devis in 1986. The theory holds that, when a new device is introduced to consumers, different influences are affecting their decision to use it. According to this principle, operational productivity has not been increased until staff adopts the technology. The implementation of some advancement or in particular focused on information technology involves investment in computer-based tools to facilitate decision-making and contact planning. It is also very important that institutional choice and logic be defined for the programs.

\subsubsection{The Extent of Using E-recruitment System}

In this objective, the researcher sought to examine the extent to which Moshi Catholic Diocese uses an erecruitment system in acquiring new employees in their respective Schools and Hospitals.it has been revealed that the Moshi Catholic Diocese uses a website, recruitment portal, and social media platforms such (LinkedIn, WhatsApp groups, Facebook, and others) to promote the free vacancies in their respective Schools and Hospitals. The rapidity of disseminating information through social media has made these networks important in not only connecting people but also in meeting people and their future employers. The findings show that the recruitment portals are mostly preferred by the MCD. Through this study, it has been exposed that, MCD succeeded to employ e-recruitment in recruiting intellectual staff to fill the empty vacancies in schools and hospitals under the diocese. However due to some limitations such as technical issues and network as well as the confidentiality of some positions traditional recruitment has opted instead.

\subsubsection{The Benefits of E-recruitment System to MCD}

In this objective, the study thought to examine the benefits gained by the Moshi Catholic Diocese recruitment team after implementing e-recruitment methods. The responses gathered from the study participants who are the part and parcel of the diocesan recruitment board were coded, effectively cleaned, and analyzed in form of frequencies, percentages, mean and standard deviations. The study findings revealed that e-recruitment is economically effective as it uses fewer expenses in advertising compared to traditional approaches. The results of this study showed that e-recruitment found to be is easier in enlisting selected candidates for an interview than traditional approaches. Likewise, the findings show that is easy to notify the applicant through the same platform applied because of having his/her information link directly on his job application something that is not easy in traditional methods. revealed that e-recruitment is more, easily assessable, reliable, and affordable than any other recruitment method, based on cost and time effectiveness in processing job applications and reviewing candidates qualifications

\subsubsection{Challenges Associated with E-recruitment}

In this objective, the researcher sought to examine the challenges encountered by MCD in the implementation of e-recruitment. The findings were grouped into challenges associated with the advertisement, enlisting, and interviewing candidates. The study findings revealed that the MCD recruitment team is facing some limitations in attracting the right candidates and navigating online recruiting tools. Additionally, technology issues and lack of proficient staff with good creativity in poster design limited the effectiveness of e-recruitment. Other limitations in advertisement include; attracts fraudulent applicants and miss out on great employees. The study pays close attention to interviews and questionnaires findings concerning the challenges associated with interviewing candidates through online platforms. The findings 
revealed that internet access is the most drawback faced as the candidate must have access to a computer and strong internet access to facilitate an online interview. In addition to this, poor internet connection had led to unexpected disruption during an interview while other times they fail at all to proceed due to severely low connection.

\subsection{Conclusion}

The findings offered further evidence to support several assertions regarding e-recruitment in the works of literature. Overall, the data indicated that the internet is a beneficial and cost-effective source of recruiting for organizations. The study found that Schools and Hospitals under Moshi Catholic Diocese use erecruitment methods as a recruiting tool at a higher rate than traditional recruitment methods. The most prevalent e-recruitment tools include recruiting agencies, social networking platforms, and job boards, which have transformed the way potential applicants, apply for vacant positions. If HR managers want to compete for talent, they must start taking e-recruitment wisely and work on it as an essential part of their company strategy. The findings revealed that the Moshi Catholic Diocese utilized the e-recruitment system effectively as a hiring tool. E-recruitment system offers several advantages, and these common advantages have been identified in numerous e-recruitment works of literature, as addressed in the empirical review section such as accessibility to passive candidates, affordability, time-saving and limited resources used. Moreover, the stability of internet connection to both parties had also interfered with an online conversation to some extent hence influence some of the interviews to be postponed. The study had also exposed that, during advertisement of empty vacancies sometimes it happened that, many candidates apply for the job in which majority of them do not follow application instructions given hence leads to the existence of a large number of unqualified applicants

\subsection{Recommendations}

\subsubsection{Recommendation for Action}

So often it has been noticed that, once email is used, applicants are applying for the outdated vacancies hence leads to great distraction during the application sorting process. Therefore, the study recommends those who wish to apply for the advertised posts through online sources read instructions given properly and ask for assistance from the experienced person during the application stage. Moreover, the study advises the organization to try to create the checklist in the application platforms they use to facilitate easier checkout for the prospective employee and to the recruitment team during reviewing stage.

\subsubsection{Recommendation for Further Study}

Given the fact that this one study can not complete everything related to e-recruitment system, the completion of this study provides opportunities and loop holes for other studies to be done concerning erecruitment strategies in various institutions locally and even abroad. This study recommends further research on the benefits of outsourcing e-recruitment issues in religious institutions. The conduct of research over the past decade will help religious institutions see the benefits and disadvantages that can be gained if they let the recruitment agencies do the work on their behalf.

\section{References}

1. Akila, B., \& Thirumagal, P. G. (2020). Effectiveness of E-Recruitment for Man Power Selection Process. in Journal of Critical Reviews. Https://Doi.Org/10.31838/Jcr.07.05.57

2. Almalki, S. (2016). Integrating Quantitative and Qualitative Data in Mixed Methods ResearchChallenges and Benefits. Journal of Education and Learning. Https://Doi.Org/10.5539/Jel.V5n3p288

3. Belisari, S., \& Appolloni, A. (2020). E-Procurement Adoption: a Case Study about the Role of Two Italian Advisory Services. Sustainability $\quad$ (Switzerland), 12 (18), 1-18. Https://Doi.Org/10.3390/SU12187476

4. Bhaktimayanand, N. (2010). Recruitment and Selection Process. Balaji E-Knowledge.

5. Bogatova, M. (2017). IMPROVING RECRUITMENT, SELECTION, AND RETENTION OF Case: Dpointgroup Ltd. February.

6. Chesney, T. (2012). Opening the Black Box of PU: An IS Approach To Defining and Measuring Usefulness. SSRN Electronic Journal. Https://Doi.Org/10.2139/Ssrn.1558619

7. Christophe, M., Elie-Dit-Cosaque, C. M., \& Straub, D. W. (2011). Opening the Black Box of System Usage: User Adaptation To Disruptive IT. European Journal of Information Systems. 
Https://Doi.Org/10.1057/Ejis.2010.23

8. Chunguli, O. (2003). a Survey of E-Recruitment Practices a Management Research Project Submitted in Partial Fulfillment of the Requirements of the Degree of Master of Business Administration of the University of Nairobi.

9. Chuong, E. B., \& Feschotte, C. (2017). Regulatory Activities of Transposable Elements: From Conflicts To Benefits. in Nature Reviews Genetics. Https://Doi.Org/10.1038/Nrg.2016.139

10. Cohen, L., Manion, L., \& Morrison, K. (2005). Research Methods in Education (Fifth). Taylor \& Francis E-Library.

11. Cohen, L., \& Morrison, K. (2017). Research Methods in Education. Eighth Edition. in Research Methods in Education.

12. Creswell, J. W. (2014). Research Design: Qualitative, Quantitative and Mixed Methods Approaches (4th Ed.). English Language Teaching.

13. Dey, A. K., \& Ramos, C. (2009). Thematic Issue On Contribution of Artificial Intelligence To Ambient Intelligence. in Journal of Ambient Intelligence and Smart Environments. Https://Doi.Org/10.3233/AIS-2009-0029

14. Duval, S., \& Wicklund, R. A. (1972). a Theory of Objective Self Awareness. a Theory of Objective Self Awareness.

15. Erba, J., Ternes, B., Bobkowski, P., Logan, T., \& Liu, Y. (2018). Sampling Methods and Sample Populations in Quantitative Mass Communication Research Studies: a 15-Year Census of Six Journals. Communication Research Reports. Https://Doi.Org/10.1080/08824096.2017.1362632

16. Fachrizal, M. R., \& Manik, A. (2019). Development of E-Recruitment As a Decision Support System for Employee Recruitment. IOP Conference Series: Materials Science and Engineering. Https://Doi.Org/10.1088/1757-899X/662/2/022018

17. Fred, M. O., \& Kinange, U. M. (2018). Effectiveness of E-Recruitment in Organization Development. Management and Economic Journal.

18. George, R. L. (2014). a Critical Investigation of Recruitment and Performance Management in the Import and Export Industry in Cape Town, South Africa. February.

19. Gronmo, S. (2020). Social Research Methods: Qualitative, Quantitative and Mixed Methods Approaches. in SAGE Publications Ltd.

20. Innocent, R., \& Kalaskar, P. B. (2016). the Adoption of E-Procurement and Its Impact On the Procurement Performance of Selected Telecommunication Companies in Rwanda. European Journal of Business and Management, 8 (15), 125-133.

21. Irabor, I. E., \& Okolie, U. C. (2017). E-Recruitment: Practices, Opportunities and Challenges. 9 (11), 116-122.

22. Jiarakorn, H., \& Pasipol, S. (2015). Development of Recruitment and Selection Process for Assistant Teachers Using Multiple Approaches. Procedia - Social and Behavioral Sciences. Https://Doi.Org/10.1016/J.Sbspro.2015.04.717

23. Kaur, P. (2015). E-Recruitment: a Conceptual Study. International Journal of Applied Research.

24. Kothari, C. . (2017). Research Methodology Methods and Techniques. in BMC Public Health.

25. Lipumba, I. (2018). brightermonday. Top Hiring Challenges for Employers in Tanzania. Https://Www.Brightermonday.Co.Tz/Blog/Hiring-Challenges/

26. Macarthur, D. (2001). PLACE AND EXPERIENCE: a PHILOSOPHICAL TOPOGRAPHY. Philosophical Review. Https://Doi.Org/10.1215/00318108-110-4-632

27. Meijer, A. (2015). E-Governance Innovation: Barriers and Strategies. Government Information Quarterly. Https://Doi.Org/10.1016/J.Giq.2015.01.001

28. Melanthiou, Y., Pavlou, F., \& Constantinou, E. (2015). the Use of Social Network Sites As An ERecruitment Tool. Journal of Transnational Management. Https://Doi.Org/10.1080/15475778.2015.998141

29. Mohammed, S. (2013). Adaptation of E-Procurement and Value Addition To Tanzania Public Institutions, a Case of Tanzania Public Institutions (Vol. 53, Issue 9). Mzumbe University.

30. Mugenda, A., \& M. (2009). Research Methods: Quantitative and Qualitative Approaches. in Acts Press Publishers.

31. Nkondola, A. A., \& Van Deuren, R. (2017). Human Resource Management Challenges in Technical and Vocational Education in Developing Countries: the Case Study of Technical Institutions in 
Tanzania. International Journal of Business and Social Science, 8 (2), 156-162. Https://Www.Ijbssnet.Com/Journals/Vol_8_No_2_February_2017/18.Pdf

32. Oboi, S. C. U. (2016). Influence of E-Recruitment Implementation On Employee Selection and Recruitment At Kisii in Kenya. November.

33. Pavitra, D. (2018). E-Recruitment: a Roadmap Towards E-Human Resource Management. Journal of Arts, Science \& Commerce.

34. Reis, J., \& Melão, N. (2020). Artificial Intelligence Research and Its Contributions To the European Union's Political Governance: Comparative Study Between Member States. Social Sciences. Https://Doi.Org/10.3390/Socsci9110207

35. Rwezahura, J. (2015). the Impact of External Factors On the Employees Selection Methods. Https://Yourbusiness.Azcentral.Com/Impact-External-Factors-Hr-Selection-Methods-27633.Html

36. Tambe, P., \& Yakubovich, V. (2019). Artificial Intelligence in Human Resources Management: Challenges and a Path Forward. California Management Review. Https://Doi.Org/10.1177/0008125619867910

37. Thomas, C. (2019). Artificial Intelligence Will Take Over Human Resources Recruitment and Selection. Network Intelligence Studies.

38. UNCTAD. (2019). the Least Developed Countries Report 2019. in Journal of Visual Languages \& Computing.

39. URT. (2015). Tanzania Unemployment Rate. Tanzania National Bureau of Statistics. Http://Www.Tradingeconomics.Com/Tanzania/Unemployment-Rate

40. Van Doesum, K. T. M., Riebschleger, J., Carroll, J., Grové, C., Lauritzen, C., Mordoch, E., \& Skerfving, A. (2016). Successful Recruitment Strategies for Prevention Programs Targeting Children of Parents With Mental Health Challenges: An International Study. Child and Youth Services. Https://Doi.Org/10.1080/0145935X.2016.1104075

41. Yang, D., Li, L., Jiang, X., \& Zhao, J. (2020). the Fit Between Market Learning and Organizational Capabilities for Management Innovation. Industrial Marketing Management. Https://Doi.Org/10.1016/J.Indmarman.2019.12.007

42. Yin, R. K. (2017). Case Study Research and Applications: Design and Methods. Sage Publications, 53. Https://Doi.Org/10.1016/J.Jada.2010.09.005 